Journal of Sustainability Perspectives

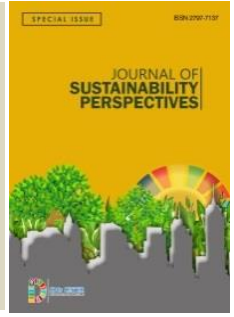

\title{
A Collaborative Approach to Planning
}

\author{
Julie Davis ${ }^{1, *}$, Alison Scholl ${ }^{2}$ \\ ${ }^{1,2}$ Trent University, 1600 West Bank Drive, Peterborough Ontario. K9L 0G2. Canada \\ *corresponding author: juliedavis@trentu.ca
}

\section{Article Info}

Received:

15 March 2021

Accepted:

25 May 2021

Published:

1 August 2021

DOI:

Presented in The $6^{\text {th }}$ International (Virtual) Workshop on UI GreenMetric World University Rankings (IWGM 2020)

\begin{abstract}
To reflect Trent University's academic leadership in environmental and indigenous studies, Trent has undertaken a collaborative campus stewardship and land-use planning process that prioritizes collection of Indigenous Traditional Knowledge (ITK) and engagement with the local First Nations. Trent's Symons campus is rich in natural and cultural assets, with drumlins, wetlands, woodlands, meadows and farmland, and diverse flora and fauna. A primary goal of the campus plan is to conserve biological diversity, maintain ecological functions, and sustain ecosystem services across more than 560 hectares, whilst enabling campus expansion and joint benefit infrastructure projects to move forward efficiently and effectively. Trent's experience in bringing ITK to the forefront of campus stewardship and land-use planning warrants critical examination to advance promising practices for conservation of biodiversity through a collaborative approach to planning.
\end{abstract}

\section{Keyword:}

indigenous traditional knowledge, planning, engagement, collaboration, biodiversity conservation

\section{Introduction}

In 2017, Trent University was challenged to update the Symons campus master plan in a way that reflected its leadership in environmental and Indigenous studies. Wetland protection, conservation of biodiversity and in particular, species at risk, and wildlife road mortality were key issues of concern, along with a desire to see ITK and the local First Nation communities play a visible and meaningful role in the planning process. In response, Trent formally launched an update to the campus plan that would bring together the Nature Areas Stewardship Plan (2002) and the Trent Lands Plan (2013) into one integrated stewardship and land-use planning framework built on a deep understanding of the land and the landscape.

The incorporation and valuing of ITK required Trent's planning team to address a variety of issues and challenges. These included developing an understanding of the local treaty rights, building trusting and respectful relationships with the communities and their elected and traditional leadership, and creating culturally appropriate engagement approaches. The outcomes have included a richer understanding by the planning team and 
University administration of the Indigenous world view, the addition of ITK into natural heritage studies, a joint commitment to continued engagement, and a more collaborative approach to natural heritage stewardship and advancing new developments on the campus.

\section{Historical Context}

\subsection{Michi Saagiig}

Trent University is located on the treaty and traditional territory of the Michi Saagiig (Mississauga) Anishnaabeg. There are four Michi Saagiig First Nation communities within the geographical area served by Trent University. The Michi Saagiig people have resided on the land around Lake Ontario until European settlers, in competition for resources and control of the lands, pushed the First Nations inland to Lake Huron. Around 1670, the Michi Saagiig returned to their lands and in time, participated in multiple treaties with the European settlers, signing Treaty 20 in 1818 and the Williams Treaty in 1923. A central philosophy of the Anishnaabeg people is to care for Mother Earth and speak for the living things than cannot speak for themselves [1].

\subsection{Trent University}

Trent University was founded in 1964, with a donation of 40 hectares of land from Canadian General Electric along the banks of the Otonabee River in the working-class rural town of Peterborough, Ontario. The founding board and president, anticipating future growth of the campus, purchased, or as necessary expropriated, more than 500 acres of agricultural land and farm properties to create a large, contiguous campus.

Founded with a core focus on a liberal arts and sciences education, the environment has always been a central theme and strength of the University. Trent was the first university in Canada to achieve accreditation from ECO Canada for its environmental program - a national standard for excellence in environmental education, and in 2017, Trent was one of the partners that collaborated on a successful bid to be declared a UNESCO Regional Centre of Expertise (RCE) on Education for Sustainable Development. Trent is also home to Canada's first Indigenous studies program, and has a legacy of leadership in Indigenous education, including developing the first Indigenous PhD program and hiring Elders as faculty. Bringing these two areas of strength together, Trent developed an Indigenous Environmental Studies and Sciences (IESS) program which remains unique to the Canadian post-secondary sector.

\section{Natural Heritage Landscape}

The Symons campus is located in the Peterborough Drumlin Field spanning the Otonabee River which forms part of the Trent Severn Waterway in the Great Lakes Basin. Natural heritage has been shaped by the area's history as a settlement area for logging, with large swaths of land cleared for lumber and agriculture. Wetlands are a prominent feature on the campus, with one provincially significant wetland (Nassau Mills PSW Complex) and further unassessed forested and marsh wetlands. Vegetation communities are typical and reflective of succession from agricultural uses. Some lands remain actively farmed. Fauna is typical for this area, given the human influences on the land. Amphibians, reptiles, fish species, mammals and bird species are documented in field observations and secondary source data. Eight species at risk (endangered or threatened status) and eight special concern species have been recorded on the land [2]. 


\section{Campus Planning}

\subsection{History of Trent University Campus Plans}

The 1964 original Campus Master Plan envisioned a core cluster of academic and student buildings, thoughtfully integrated with the natural environment, surrounded by 12 'villages' that brought the University and the growing town of Peterborough together. Over time, the campus lands were categorized into Core Campus, comprised of academic and administrative operations; Nature Areas, meant to promote biodiversity, teaching and research on the land, and community recreation; and Endowment Lands, parcels earmarked for potential future developments due to their proximity to road access and municipal servicing.

The 2002 Nature Areas Stewardship Plan [3] was created to guide active stewardship of Trent's 12 Nature Areas. An underlying concern prompting the development of this plan was 'the potential loss of biodiversity of habitats for future academic study and research, and for recreational and therapeutic access by the campus and community at large' [3]. The 2006 Endowment Lands Plan [4] provided a framework for future development of the Endowment Lands. The 2013 Trent Lands Plan [5] built on the 2006 Endowment Lands Plan [4] with a specific focus on two initiatives, a research park and a municipal arena, and where they should be located on the campus.

\subsection{Trent Lands and Nature Areas Plan}

In 2017, Trent initiated a new and innovative approach to campus planning to guide the stewardship of the natural lands and to meet the Board of Governor's strategic obective to 'advance thoughtful and appropriate development on Trent Lands guided by an updated Trent Lands Plan' [6]. The expressed intent was to 'take an ecosystem approach' to integrate Nature Areas stewardship with the land-use framework plan, to document natural features and species to be considered in the context of land-use plans, and to identify natural areas to be considered for rehabilitation and restoration. Further, development of the plan was to include engagement with the campus community, local First Nations, members of the local community, and alumni, with a focus on collecting and integrating ITK. Trent's academic leadership and commitment to the environment and Indigenous studies were at the forefront in designing this planning approach, as was the local, national and international focus on biodiversity, climate change, and protection of the environment. The campus plan is in the final stages of development and will be presented to the Board of Governors for approval in December 2020.

\section{Indigenous Engagement}

\subsection{Planning Process}

At the inception of the planning process, a request for proposal for consultants to lead the campus planning was issued by the University. The winning proponent included an Indigenous engagement consultant who subsequently advised on and led engagement with the University, Indigenous students and faculty, and the local communities. Their approach was based on Indigenous-led engagement, a respect for the diversity of Indigenous peoples and perspectives, and building a foundation in Indigenous teachings and values. The plan included formation of an Indigenous steering group (the recently constituted Trent University Elders and Traditional Knowledge Keepers Council fulfilled this role), 
Gikendamowin Akiing (Knowledge from the Land) campus walks, Indigenous sharing meetings, and ITK workshops.

\subsection{Treaties}

A fundamental underpinning of the Indigenous engagement process was recognition of the treaty lands on which Trent University is located and the associated treaty rights of the local First Nations. Across the country, the litigation and settlement of treaty rights was a critical context for Trent's plans. Local First Nations had expressed greater interest in landuse decisions in the Peterborough area, exerting their role as rightsholders, and in 2018 the Alderville litigation was settled recognizing the First Nation's continuing treaty harvest rights in the area that includes Trent University's Symons campus.

\subsection{Protocol and Teachings}

To build a trusting environment in which to receive traditional knowledge, the Trent planning team spent time learning about the local treaties, Anishnaabeg belief systems, and Michi Saagiig traditions and protocols. Some of this learning was codified into a protocol guide book [7] describing, for instance, the significance of offering of tobacco to an Elder to request their time and participation, and to honour their wisdom. A meal was served as part of planning and engagement meetings to allow the relationship to develop while sharing food, as feasting together is an important element of Michi Saagiig culture. Meetings always began with a smudge and an Elder offering a blessing to start the meeting in a good way. The Trent Lands and Nature Areas Plan began with a small private Indigenous ceremony to give thanks to the land and to the water, and to ask permission of Mother Earth to begin the field work required to complete the plan. A ceremony will also mark the completion of the planning process.

\subsection{Collection of ITK and Indigenous Interests}

Michi Saagiig Elders and knowledge holders shared oral knowledge of the Trent Lands with the planning team during one-on-one discussions, Elders and Traditional Knowledge Keepers Council meetings, and during a traditional knowledge workshop. Knowledge shared included Indigenous ways of knowing, cultural and ecological land features and priorities, significant species' habits and habitats, and observed changes on the land over time. It was emphasised that this information was shared to assist in the planning process for the benefit of the land. At the request of the Elders, sensitive information (such as the location of species at risk or cultural sites) will not be made public by the University, and the protection of such sensitive information is overseen by the Elders and Traditional Knowledge Keepers Council.

Trent began hosting meetings with Consultation Liason Officers from the local First Nations as a forum to discuss proposed and active developments on campus, but also to share progress on and gather input to the Trent Lands and Nature Areas Plan. The Consultation Liason Officers provide liaison services between their First Nation and organizations proposing developments, to assess if there may be impacts to treaty and aboriginal rights. Traditional knowledge was also shared during these meetings, as was the Michi Saagiig interest in continuing to harvest traditional medicines and engage in ceremony on Trent Lands, and the expectations for Trent to be a good steward and protector of the natural environment. 


\subsection{Barriers and Challenges}

The most fundamental challenge encountered in collecting Indigenous Traditional Knowledge and engaging with Indigenous people in the planning process was a lack of trust. At the inception of the process, Indigenous people emphasized the need to build trust before seeking their time and contributions to the process. Lack of trust had arisen through concern about past land-use decisions, lack of clarity on governance processes for land-use decisions, and a perception that the University had a poor understanding of treaty issues and needed to do more recognize the Michi Saagiig First Nations as the traditional people of the area.

An Indigenous knowledge sharing workshop was held to gather Indigenous knowledge from students, faculty and local Indigenous people. Instead, participants questioned past land use decisions, lack of involvement of Indigenous voices in those decisions, and the need for the University and planning team to understand the Indigenous cultural and spiritual perspective of the land, flora, fauna and especially water, before the community was willing to share their knowledge. In proposing principles for landscape approaches to reconcile conservation with competing land uses, Sayer et al., [8] note the alignment of goals and objectives amongst parties is an essential 'common concern entry point' to build trust. When beliefs, values and objectives are not aligned, trust is difficult to achieve and parties will struggle to develop confidence in the process. The Michi Saagiig see one of their primary objectives is to protect Mother Earth, and they needed confidence in Trent's commitment to this goal too.

In addition to the need to build a trusting relationship prior to asking for insights and guidance, was the expectation from local First Nations that the communities be brought into planning processes prior to any decisions being made. As they pointed out, consultation with First Nations should happen first, as they are rightsholders and not just a box to be ticked in the land planning process. Building the relationship and opening dialogue in the early stages is expected in order to build trusting, mutually beneficial relationships.

Challenges emerged between evidence-based scientific survey and traditional knowledge shared orally. Additionally, the concept of the sacredness of knowledge within Indigenous communities limited how and with whom traditional knowledge information and insights could be shared. Working within the university setting, where academics expect to be able to examine, question and replicate the work of their peers, accepting traditional knowledge required flexibility from the University and the consulting team, especially as this is the first time ITK had been collected for a planning process.

\subsection{Emerging Promising Practices}

Building trust with Indigenous peoples throughout this planning process required visible support from the leadership of the University. Trent's Board of Governors set out a nine point plan to advance a mutually beneficial and respectful relationship with the Michi Saagiig First Nations, that included use of land acknowledgement, formation of the Elders and Traditional Knowledge Keepers Council, regular meetings with local chiefs and council, and development of an engagement protocol for land-use decisions. The Board and senior administration of the University participated in cultural training and received regular reports on the progress of the plan. The Chair of the Board met with local First Nation councils, and the Vice President, External Relations and Advancement engaged regularly with the elected 
chiefs to share the goals of the planning processes and to address any concerns. The Community Relations Office of the University officially adopted the role of supporting the development of this relationship, in partnership with the First Peoples House of Learning and the Chanie Wenjack School for Indigenous Studies.

The Director and the Cultural Advisor from Trent's First Peoples House of Learning (indigenous student success and support unit) assisted the Trent planning team to engage with community respectfully in culturally appropriate ways. They have been a valued and effective partner and guide as the relationship between Trent and the Michi Saagiig people has evolved and strengthened. They have participated in all meetings and Indigenous engagement events. Moreover, working with an experienced indigenous consultant to develop and implement the plan was key. This consultant was known by the local communities, which further aided in building the relationship.

Recognizing the importance of ceremony throughout the planning process has helped to foster respect and trust between Michi Saagiig communities and the University. Starting off the project in a good way with ceremony, hosting meals at every meeting, and closing with ceremony shows due respect to Indigenous culture, and the value of the land, water and biodiversity of the campus.

By placing environmental study in the first phase of the process, the University demonstrated its commitment to a different approach to land planning. Through fourseason studies, review of provincial and regional data, and incorporating knowledge from the academic and Indigenous communities, Trent was able to demonstrate a renewed commitment to the environment and the biodiversity on our lands. Using an environmentled and ecosystem approach to land use planning helped to build trust with First Nations that Trent shared their commitment to care for the land.

\section{Future Directions for Study}

The use of ITK in ecological research is still an emerging practice, and the approach varies greatly [9]. The approach described in this paper deals with the collection of ITK for land stewardship and to inform land use through a multi-year, structured engagement process. The depth of engagement with First Nations that Trent University undertook to create the Trent Lands and Nature Areas Plan appears to be at the leading edge of campus land planning processes. However, this level of engagement is now more typical and necessary for natural resource, mining and energy companies based on their Duty to Consult under federal legislation. An exploration of the approaches used in these sectors, and how it may apply to the university sector. Further, studying successful collaborations between Indigenous people and landowners to implement natural heritage management plans, including conservation of biodiversity, would be a valuable complement.

\section{Summary/ Concluding Remarks}

Trent University's mission includes the commitment to "foster an environment where Indigenous knowledge is respected and recognized as a valid means by which to understand the world" [10]. Ensuring campus planning processes include the collection of ITK is an important way to demonstrate this leadership. However, establishing a shared objective of caring for the earth, which includes the conservation of biodiversity, making a long term commitment to building trust, and engaging First Nations early and meaningfully in data collection and planning processes, are necessary prerequisites for indigenous people to share ITK. 


\section{References}

1. Williams, D. 2019. Oral communication to Trent Planning Team

2. Natural Heritage Report, 2020. Trent University. Unpublished, in draft

3. Jones, R., Fox, M.G., Marsh, J.S. 2002. The Stewardship Plan for the Trent University Nature Areas. Available online at https://www.trentu.ca/trentlandsplan/sites/trentu.ca.trentlandsplan/files/documents/ draftStewardshipPlanforTUNatureAreas2002.pdf , accessed on 17 August, 2020

4. 2006 Endowment Lands Master Plan, Trent University. Available online at https://www.trentu.ca/trentlandsplan/plan/2006-endowment-lands-master-plan accessed on 18 August, 2020

5. 2013 Trent Lands Plan, Trent University. Available online at https://www.trentu.ca/trentlandsplan/plan/2013-trent-lands-plan , accessed on 20 August, 2020

6. Board Strategic Objectives (2016-2022), Trent University. Available online at https://www.trentu.ca/governance/board-governors/objectives , accessed on 20 August, 2020

7. Michi Saagiig Protocol Guide Book, 2019. Trent University. Available online at https://www.trentu.ca/fphl/sites/trentu.ca.fphl/files/documents/TrentU MichiSaagiigG uidebook Web.pdf, accessed on 20 August, 2020

8. Sayer. J., Sunderland, T., Ghazoul J., Pfund J.L. et al, 2013. Proceedings of the National Academy of Sciences of the United States of America, Vol. 110, No. 21, pp. 8349-8356. National Academy of Sciences

9. Brook, R.K., McLachlan, S.M., 2008. Trends and Prospects for local knowledge in ecological conservation research and monitoring. Biodiversity Conservation Journal, Volume 17, pp. 3501-3512

10. Trent University Mission, Trent University. Available online at https://www.trentu.ca/about/vision-mission, accessed on 20 August 2020 